\title{
¿Qué concepción de niñez subyace en las prácticas educativas? ¿Hacia dónde queremos movernos en la educación en esta etapa inicial?
}

\author{
What conception of childhood underlies educational practices? \\ Where do we want to move in education at this early stage?
}

\section{Valeria Marsiglia* e Inés May**}

\footnotetext{
* Maestra. Licenciada en Educación Inicial. Especialista en cambio organizacional y gestión educativa. Maestranda en Educación con especialización en Gestión Educativa (Universidad Católica del Uruguay). Supervisora de Centros Educativos Infantiles Privados (CEIP) del Ministerio de Educación y Cultura de Uruguay.

$\bowtie$ vvalemars@gmail.com

https://orcid.org/0000-0003-

3919-4677

** Maestra. Magíster en Didáctica de las Ciencias Básicas (Universidad CLAEH). Doctoranda en Educación. Supervisora de los colegios maristas (educación privada) de Argentina, Uruguay y Paraguay. Formadora en el área de las Ciencias Naturales por el IFS (ANEP, CEIP).

$\triangle \cdot$ inesmayg@gmail.com https://orcid.org/0000-00021858-533X
}

RECIBIDO: 30.9 .2019

ACEPTADO: 26.10 .2019

\begin{abstract}
Resumen
El presente artículo reflexiona sobre la concepción de niñas y niños que subyace en las prácticas educativas en la etapa de 0 a 6 años. Ubicados en el paradigma de la complejidad, se intenta reflexionar acerca de la tarea de la educadora y del educador y su relación con las niñas y los niños en la realidad uruguaya. A partir de ello se profundiza y analiza el concepto de niñez que manejan las instituciones, buscando interpelar las prácticas educativas. Esto supone, entre otras cosas, plantear qué tipo de sociedad anhelamos y, de acuerdo con ello, proyectar insumos para pensar en qué tipo de educación necesitamos, a qué centros educativos aspiramos y qué formación docente se deberá asumir para coordinar con coherencia esos aspectos. Para eso se hace indispensable poner en el centro a las niñas y niños y consolidar así un cambio educativo.
\end{abstract}

Palabras clave: educación de la primera infancia, niño, formación de docentes.

\section{Abstract \\ This article reflects on the conception of girls and boys that underlies educational practices at the 0-6 age group. Based on the paradigm of complexity, it reflects on the task of the educator as well as on her or his}


relationship with children, in the Uruguayan reality. From this standpoint, the prevalent concept of childhood that exists in the classroom is thoroughly examined in order to question and challenge contemporary educational practices. This means asking what kind of society we yearn to and, according to this, planning inputs to think about what kind of education we need, what educational centers we envision and what type of teacher training should be implemented in order to coordinate these aspects coherently. This transformation necessarily puts girls' and boys' interests at the center of the process to consolidate an educational reform.

Keywords: early childhood education, children, teacher education.

\section{Introducción}

Mirar la escuela hoy, los procesos educativos que se dan allí, el contexto en que habitamos y los cambios acelerados en los que muchas veces nos encontramos nos pone en una perspectiva y una sintonía que provocan reflexiones que buscamos compartir en este texto.

Sin duda son tiempos de cambios, a veces percibidos como turbulentos, inestables, complejos, donde no existe una respuesta ni tampoco una pregunta, sino que son muchas respuestas y preguntas en torno a la temática, y no necesariamente a una pregunta se le puede brindar una respuesta lineal. Edgar Morin (Morin y Pakman, 1994), filósofo y sociólogo contemporáneo, plantea la importancia de articular y organizar los conocimientos para profundizar en el entendimiento de los problemas que tenemos en el mundo y como humanidad. La reforma de la enseñanza debe conducir a la reforma del pensamiento y viceversa, expresa el filósofo, porque se trata de una reforma paradigmática y no programática, y también porque se necesita una comprensión más profunda, dado que las soluciones a algo tan complejo no pueden ser lineales, superficiales. Entendemos que quienes estamos en las trincheras y habitamos los centros educativos formamos parte del problema. Reconocerlo y asumirlo no es fácil, ya que, como plantea Morin, forma parte del tipo de pensamiento que hay que reformar.

La idea que acercamos para compartir en este espacio tiene que ver con las niñas y los niños que acompañamos en las primeras edades de su desarrollo. Partiendo de las prácticas diarias, queremos reflexionar sobre las concepciones de niñez, de infancia e infancias, que subyacen en ellas.

El cuento que a continuación exponemos nos ayuda a introducirnos en la temática, sobre todo porque puede ilustrar planteos que muchas veces están ocultos en el quehacer diario. El cuento se llama El niño pequeño, es de una escritora y pedagoga llamada Helen E. Buckley (2013) y dice así: 
Una vez un niño fue a la escuela. El niño era bien pequeño, la escuela era bien grande. Pero cuando el niño vio que podía caminar hacia el aula desde la puerta de la calle, se sintió feliz y la escuela ya no le pareció tan grande como antes.

Poco tiempo después, una mañana la maestra dijo:

- Hoy vamos a hacer un dibujo.

— ¡Bien! — pensó el niño, porque le gustaba dibujar.

Y podía hacer todas esas cosas que le gustaban: leones y tigres, gallinas y vacas, trenes y barcos. Así que tomó su caja de lápices de colores y se puso a dibujar.

Pero la maestra dijo:

— ¡Esperen! ¡Todavía no es hora de comenzar!

Y el niño esperó hasta que todos estuvieran listos.

- Ahora sí —dijo la maestra-. Hoy vamos a dibujar flores.

— ¡Qué bien! —pensó el niño, porque a él le encantaba dibujar flores. Y comenzó a dibujar flores muy bonitas con su lápiz rosa, naranja y azul.

Pero la maestra interrumpió y dijo:

— ¡Esperen! Yo les mostraré cómo hay que hacerlas. ¡Así! — dijo dibujando una flor roja con el tallo verde- ¡ ¡Ahora pueden comenzar!

El niño miró la flor de la maestra y luego miró la suya. A él le gustaba más su flor que la de la maestra, pero no dijo nada. Simplemente guardó su papel, cogió otro e hizo una flor como la de la maestra: roja, con el tallo verde.

Otro día, cuando el niño llegó al aula, la maestra dijo:

— ¡Hoy vamos a trabajar con plastilina!

— ¡Bien! — pensó el niño. Podía hacer todo tipo de cosas con plastilina: gatos y muñecos de nieve, elefantes y conejos, coches y camiones... Y comenzó a apretar y a amasar la bola de plastilina. Pero la maestra interrumpió y dijo:

— ¡Esperen! No es hora de comenzar.

Y el niño esperó hasta que todos estuvieran listos.

- Ahora — dijo la maestra - vamos a hacer una serpiente.

— ¡Bien! —pensó el niño. A él le gustaba hacer víboras. Y comenzó a hacer algunas de diferentes tamaños y formas. Pero la maestra interrumpió y dijo:

— ¡Esperen! Yo les enseñaré cómo hacer una serpiente larga. Así... —-mostró la maestra. ¡Ahora pueden comenzar!

El niño miró la serpiente que había hecho la maestra y después miró las suyas. A él le gustaban más las suyas que las de su maestra, pero no dijo nada. Simplemente volvió a amasar la plastilina e hizo una serpiente como la de la maestra. Era una serpiente delgada y larga. De esta manera, el niño aprendió a esperar y a observar, a hacer las cosas siguiendo el método de la maestra.

Tiempo más tarde, el niño y su familia se mudaron a otra casa, en otra ciudad, y el niño fue a otra escuela. 
Esta era una escuela mucho más grande que la anterior. También tenía una puerta que daba a la calle, y un camino para llegar al aula. Esta vez había que subir algunos escalones y seguir por un pasillo largo para finalmente llegar allí.

Justamente ese primer día que el niño estaba allí por vez primera, la maestra dijo: - Hoy vamos a hacer un dibujo.

—Bien — pensó el niño. Y esperó a la maestra para que le dijera cómo hacerlo. Pero ella no dijo nada, solamente se limitaba a caminar por el aula.

Cuando se acercó al niño, la maestra dijo:

- ¿Y tú no quieres dibujar?

-Sí, pero ¿qué vamos a hacer? — dijo el niño.

—No lo sabré hasta que tú lo hagas — contestó la maestra.

- ¿Pero ¿cómo hay que hacerlo? Volvió a preguntar el niño.

— ¿Cómo? - dijo la maestra-. De la manera tú que quieras.

- ¿Y de cualquier color? - preguntó el niño.

—De cualquier color — dijo la maestra y agregó-: Si todos hicieran el mismo dibujo usando los mismos colores... ¿cómo podría yo saber de quién es cada dibujo y cuál sería de quién?

—No sé... — dijo el niño. Y comenzó a dibujar una flor roja con el tallo verde.

Sin afirmar que esto es lo que sucede siempre, porque sabemos y reconocemos el valor y el profesionalismo de muchas educadoras y educadores, no queremos pecar de inocentes y mirar hacia otro lado, cuando también somos conscientes de que la rutinización y escolarización de prácticas en educación inicial buscan preparar a las niñas y niños para la escuela primaria. En la experiencia transitada encontramos que muchas actividades y propuestas que se ofrecen a las niñas y niños en estas edades están impregnadas de planteos que remarcan la importancia de preparar al niño para su ingreso a la etapa escolar, lo que lleva a poner énfasis en aspectos que quizás no deberían demandar tanto tiempo y preocupación de las educadoras y educadores, como la lectoescritura y la numeración, entre otros.

La atención en los centros educativos por momentos se ha focalizado y preocupado por promover una propuesta que muchas veces no tiene en cuenta el tiempo que niñas y niños necesitan para aprender, para jugar, para descubrir, para hacer.

Estamos hablando de la pedagogía y la didáctica implicadas en la relación del educador con el educando, es decir, en palabras de Meirieu (2001, p. 96):

Lo ideal es poder responder, en cada caso, para cada sujeto en proceso de aprendizaje a la pregunta siguiente: teniendo en cuenta el nivel previo del sujeto, las limitaciones específicas del objeto, ¿qué tareas se pueden proponer de modo que, al efectuarlas, el sujeto encuentre un obstáculo, pueda hacer de ello un problema 
y lo resuelva por sí mismo, con el fin de adquirir una habilidad cognitiva nueva, que pueda ser movilizado frente a otros problemas que se habrán identificado conforme tienen las mismas características?

La etapa de 45 días a 2 años es de exploración y descubrimiento a través de los sentidos. Lo que niñas y niños puedan tocar, llevarse a la boca, experimentar con su cuerpo estimula el conocimiento de sí mismos y del ambiente. Poco a poco, a medida que van creciendo, van descubriendo a un otro y comienzan a tener más interacciones. En otras palabras, por medio de los estímulos y en la interacción con los demás, las niñas y los niños interactúan con el medio que los rodea.

Una situación didáctica supone, en primer lugar, que se haya definido un objetivo de aprendizaje en referencia, a la vez, a un programa determinado y a un nivel de desarrollo cognitivo alcanzado por el sujeto; supone, sobre todo, que es posible una intersección entre estos dos campos. Una situación didáctica exige también que se haya identificado una tarea que pueda, a la vez, movilizar el interés del sujeto y hacer emerger un obstáculo que el objetivo permitirá superar; y aun así, la existencia de una tarea que combine, de modo certero, estas dos existencias no es una garantía por adelantado. (Meirieu, 2001, p. 96)

A partir de ello nos preguntamos: ¿qué concepción de niño/a subyace en un tipo de planteo en el que se priorizan o se piensan actividades sin una intención clara? o ¿dónde se pone de manifiesto la idea de que el niño es receptor de aquello que ignora, o que es el adulto el que conoce las necesidades que tiene la niña o el niño y las formas en las que puede y a veces debe aprender/construir?

Los invitamos a volver sobre la palabra educar. Rastreando su etimología, encontramos que viene del latín educere, que significa 'sacar', 'extraer', 'conducir de adentro hacia afuera'. Asimismo, el verbo educare, también del latín, hace una referencia más explícita a la acción de establecer una guía para que el sujeto «salga por sí mismo de un estado» («Educar», 2019). Sobre estas consideraciones es que el término educare fue incorporando la idea de brindar a un sujeto todos los medios para que pueda salir por sí mismo de su primitivo estado a una plenitud más elevada. La reflexión sobre la etimología de la palabra nos muestra que la representación de una posible acción es distinta de la que tenemos hoy en nuestro imaginario.

Si pensamos en una acción actualizada, asociada a la acción de educar, ¿qué se nos representa? ¿La asociamos a una actividad más bien intelectual, en la que el que no sabe es el destinatario pasivo de las propuestas de un otro que sabe más y que por tanto enseña? 
¿Nos reconocemos hoy los educadores en general como provocadores y acompañantes de aprendizajes? ¿Cómo nos sentimos con nuestra tarea?, ¿siempre conformes, profesionales? ¿Percibimos la necesidad de cambiar, de hacer que otra cosa suceda en las aulas? ¿Por qué?

Estas preguntas nos interpelan como promotores de cambios y nos invitan a eso... a ser profesionales que despliegan en su hacer y reflexión un horizonte diferente para la educación, porque las niñas y niños lo necesitan, al igual que la sociedad en su conjunto.

En la sociedad del conocimiento actual, con sus amenazas y sus oportunidades, el papel de la educación y los educadores es clave: los educadores son agentes fundamentales en esta sociedad. Sin una acción decidida en la educación la sociedad del conocimiento se convertirá en una sociedad más desigual, más desinformada y más excluyente. (Doménech, 2019, p. 18)

Creemos que parte de nuestra tarea como educadores es trabajar en la autonomía de las niñas y niños. Para Meirieu (2001, p. 97):

[...] solo existe autonomía en la medida en que un sujeto ha adquirido la capacidad de utilizar de manera pertinente una herramienta cognitiva, es decir, de asociarla a situaciones en las que habrá identificado un problema para el cual conoce la eficacia de esa herramienta... Una vez adquirido todo esto, finalmente hay que añadir que la didáctica no puede ahorrarse tomar en cuenta las diferencias individuales, ¡tanto en el plano de las representaciones como en el de las estrategias cognitivas!

¿Realmente nuestras prácticas impactan en el logro de nuestros objetivos? ¿Existen prácticas pedagógicas cuyo centro está puesto en el producto, en un producto que pone el énfasis en la homogeneización, sin apelar a la creatividad, sin un sentido para el niño, donde el único criterio válido es el que señala el adulto? De ser así, nos alejamos de los objetivos planteados y de la posibilidad de acercar a niñas y niños otra propuesta. Esta debe hacer posible descubrir e interpretar el mundo en el que están insertos, que los invite y motive a explorar, a preguntar y preguntarse, a investigar, a construir hipótesis, que les proponga el juego como forma de su aprendizaje y manera de expresión. De no ser así, como educadores, perdemos la oportunidad de conocerlos más, de observar cómo aprenden mejor, de interpretar sus necesidades, intereses, motivaciones; nos perdemos la oportunidad de hacer una verdadera escucha. 
Escucha como metáfora de la disponibilidad, sensibilidad a escuchar y a ser escuchados; escucha no solo con el oído, sino también con todos los sentidos (vista, tacto, olfato, gusto, orientación). (Rinaldi, 2001, p. 24)

\section{¿Qué imagen de niña y niño tenemos?}

Como expresa Rinaldi (2001, p. 7), es difícil encontrar respuestas absolutas a preguntas tan importantes y profundas, pero cada uno de nosotros es portador de una imagen de niño y, por tanto, de «teorías educativas propias, maduradas en el interior de la experiencia personal o construidas o adquiridas como patrimonio social y cultural al cual referirnos».

Pensar y actuar en educación implica, entre otras cosas, reflexionar sobre la concepción de niña y niño que tenemos.

El Marco curricular para la atención y educación de niños y niñas uruguayos desde el nacimiento a los seis años acompaña una concepción de niño/a y la expresa de la siguiente manera:

El niño/la niña es un sujeto de derechos, una persona proactiva, portadora de un rico potencial y dotada de iniciativa, con capacidad de realizar sus propias opciones en los procesos personales de desarrollo y aprendizaje, en relación con personas adultas, pares, objetos y el entorno natural y cultural del que forma parte. Sus búsquedas motivadas por intereses e interrogantes se caracterizan por la singularidad que siempre está presente en cada niño/niña. Ocurren en un tiempo histórico y en un espacio situado, en un marco de valores que busca el bien común y en una cultura específica de pertenencia, con apertura y respeto por la multiculturalidad. Por ello es necesario comprender y atender la diversidad presente en la infancia como grupo humano con intereses, fortalezas, necesidades y características propias, personalizando las intervenciones en pro del máximo desenvolvimiento del potencial de cada niño/niña. (Uruguay Crece Contigo [UCC] y Consejo Coordinador de la Educación para la Primera Infancia [CCEPI], 2014, p. 12)

Esta definición nos permite ver a la niñez como etapa, como parte de una comunidad, con intereses propios en relación con su entorno, lo que es totalmente contradictorio con la visión de niñez y de niño como sujetos que no saben nada y que por tanto todo se les debe enseñar. Como hemos planteado, aún se observan resabios de este concepto. Creemos que está en nosotros, en todos los que trabajamos en el área educativa, el generar el cambio y continuar apostando a repensar nuestras prácticas y por qué hacemos lo que hacemos, en pro de una mejor calidad de la educación. 
Asimismo, concebir a las niñas y niños como sujetos de derecho nos lleva a tomar en cuenta otras dimensiones fundamentales, como, por ejemplo, el derecho a aprender.

Sabemos que el aprendizaje no ocurre por transmisión ni porque alguien tuvo la intención de enseñar. Es un proceso que se construye cuando quien aprende le encuentra un sentido, un significado, cuando tiene razones y motivaciones para hacerlo y entonces va por ello. Por tanto, mirando a cada niña/o como sujeto de derecho, es fundamental «crear un estado de acogida en el contexto social y en el contexto más general en el cual el niño vive y vivirá» (Rinaldi, 2001, p. 8). En ese sentido, al volver y reflexionar sobre las prácticas educativas desde una perspectiva de derecho, lo que se invita a hacer en los espacios educativos deberá tener en cuenta estos aspectos, e invitar a que las niñas y niños puedan aprender, porque ese es también su derecho.

\section{¿Hacia dónde movernos en la educación infantil?}

Dando continuidad a la línea de Edgar Morin (2001), partimos de la base de que estamos insertos en un mundo que cambia y lo hace rápidamente. En ese contexto está inmersa la educación y por tanto urge la necesidad de cambiarla. Pero ¿qué cambiar? ¿Hacia dónde movernos?

Consideramos importante que en el centro educativo se habiliten cambios acordes a las realidades que sea posible plasmar de acuerdo al contexto en que esté inserto cada uno.

El movimiento lo asociamos a una manera de hacer escuela más comunitaria, que incluya a la familia y su contexto, y no les dé la espalda. Las familias son las primeras educadoras de los niños; ellas tienen que trabajar conjuntamente con el centro educativo, con los educadores, a favor de los procesos de sus hijas e hijos y no al revés. Por tanto, las personas implicadas en el trabajo con la niñez tendremos que aprender a trabajar también en esta perspectiva.

Ese hacer escuela también está relacionado con las propuestas que acercamos a las niñas y niños durante el tiempo que están con nosotros en el centro. Domenech Francesch (2019) reflexiona sobre los procesos educativos que se suceden en los centros poniendo el foco en la necesidad de volver a dar tiempo a los procesos de las niñas y niños, a sus aprendizajes. Aboga por una educación lenta.

Por algún motivo, en estos últimos tiempos entendimos que el cambio educativo y la mejora de la educación tenían que pasar por hacer más actividades en las instituciones, por engrosar diseños curriculares y hacerlos más densos, para que pudieran contemplar todas las necesidades que las niñas y niños iban a tener luego como adultos. Sin embargo, en palabras de este pedagogo, hoy deberíamos reivindicar el factor tiempo, hacer de los procesos que se viven en los centros educativos momentos 
disfrutables, donde el tiempo de cada uno no opere como una limitación, sino, al contrario, que sea tenido en cuenta y respetado.

La escolarización universal y obligatoria, cuando no consigue democratizar el saber y se ve supeditada a intenciones selectivas, no puede dar respuesta a su finalidad más genuina. En este mercado de la oferta y la demanda es donde encontramos la educación acelerada, los programas sobrecargados y los objetivos pensados para ser alcanzados antes de tiempo. (Domenech, 2019, pp. 15-16)

Cuando nos convertimos en docentes replicadores de un currículo, corremos ciertos riesgos que terminan repercutiendo en la calidad de la educación, impactando directamente en la infancia. ¿Acaso hoy no vemos diferentes ritmos de aprendizaje? ¿Qué hacemos con eso? ¿Cómo los abordamos?

En esa perspectiva, entendemos que no se trata de homogeneizar procesos en los niños, sino más bien tomar en cuenta las diferencias y valorar el tiempo de cada uno para aprender. Domenech (2019), en su libro Elogio de la educación lenta, plantea la necesidad que tenemos los educadores de valorar el tiempo que se necesita para aprender. Todo aprendizaje conlleva un tiempo, un tiempo de comprensión y también un tiempo de ejercitación.

Es necesaria una nueva manera de entender el tiempo. En plena sociedad del conocimiento, con una gran multiplicidad de frentes abiertos y de necesidades a las que el sistema educativo debe poder dar respuesta, seguimos teniendo un sistema en el que, de forma mayoritaria, la cantidad se impone a la calidad y la velocidad acompañada de la superficialidad excluye la profundización. (Domenech, 2019, pp. 23-24)

Somos conscientes de que cualquier cambio o transformación en educación va a estar gestionado en primer lugar por el docente, por la educadora y el educador. En este sentido, y siguiendo el planteo de Anijovich, Cappelletti, Mora y Sabelli (2008), creemos que los modelos de formación y desarrollo profesional que promueven un cambio profundo en el quehacer de la práctica son aquellos que están basados en la reflexión sobre la práctica misma. De los dispositivos que menciona la autora citada, algunos se basan en narraciones y otros en interacciones. Estos últimos atienden y promueven el intercambio y la confrontación entre pares.

Implementar estas acciones en un centro educativo podría ayudar a consolidar espacios de intercambio entre educadores, necesarios para revisar y reflexionar el sentido de lo que se propone a las niñas y los niños, así como para organizar la planificación del centro. Este es un tiempo necesario para la profesionalización como educadores. El 
tiempo para pensar el centro educativo todo, lo que queremos que suceda allí, el tipo de vivencias que queremos que tengan nuestras niñas y niños diariamente, y la articulación y el encuentro con la comunidad y las familias. En sí hablamos de una planificación estratégica de la organización.

Un centro educativo abierto a la comunidad ofrece más oportunidades para aprender. El trabajo en red, mirado desde los centros educativos, es fundamental para la calidad de la educación. También permite aunar criterios, enriquece las propuestas e impide que se superpongan esfuerzos de diferentes organizaciones con el mismo objetivo.

Pensarnos como sociedad es un desafío seguramente pendiente pero necesario, porque como fruto de esa reflexión podremos determinar el tipo de escuela que queremos y, por ende, el tipo de docentes que necesitamos. Por tanto, asumimos el valor que tiene la formación de los educadores. Son temas muy amplios que requieren discusiones en varios niveles: políticos, sociales, educativos, económicos, dado que no podemos dejar de lado que toda la sociedad educa y es responsable. De esta manera podemos asumir que los problemas de la educación y de la escuela no son solamente de quienes estamos en las escuelas (educadores, directores, maestros, padres, entre otros), sino de todos, de toda la sociedad.

Nos planteamos si se están formando educadoras y educadores capaces para trabajar con la realidad en la que viven las niñas y niños uruguayos. Esa visión/concepción ¿es la que queremos y compartimos para este momento de actualidad? Una vez que definimos cómo entendemos a la niña y al niño, manifestar los objetivos como país nos ayudará a pensar cómo tendría que ser un buen docente y los saberes que necesita para el trabajo con estas edades.

En Uruguay hemos vivido varios cambios de planes en la formación docente. El cuento que transcribimos nos interpela, sobre todo en referencia a la etapa en que nos estamos enfocando, de los 0 a los 6 años, que la neurociencia ha demostrado que es crucial para el desarrollo infantil. Cada vez más se estudia la importancia de la calidad de las relaciones que se generen entre las y los docentes con las niñas y niños (López Boo, Araujo y Tomé, 2016). El espacio edilicio es importante, pero más lo es una interacción de calidad entre los educadores y los niños. Entendemos que es allí, en el vínculo, donde incide la formación de los docentes. Este análisis que supone la formación docente requiere mayor profundidad. El educador requiere de un saber específico, de una atención cuidadosa y profesional.

La tarea de quien educa no es solo la de permitir que las diferencias se expresen, sino también de hacer posible que negocien y que se alimenten en la comparación y en el intercambio. (Rinaldi, 2001, p. 27)

Gore y Dunlap (2006, pp. 15-16) manifiestan: 
[...] la tarea de capacitación no puede ser enunciada solamente como aquella que consiste en cambiar conocimientos, sino como una labor que supone cambiar conocimientos junto con el contexto en el cual sobreviven. Esto significa también cambiar instituciones y usos arraigados.

Un aspecto no menor es la motivación de los docentes, así como la retroalimentación de su tarea en el día a día. Es interesante el planteo de Hargreaves y Fullan (2014, p. 32) cuando afirman:

La perspectiva actual de las escuelas se enfoca en el rendimiento y las calificaciones, perdiendo de vista en exceso el resto de cosas que caracterizan a la enseñanza: lo que los maestros traen a su trabajo y lo que les mantiene a ellos y a sus alumnos motivados. Esto no quiere decir que las estrategias basadas en la evidencia no sean importantes [...] El problema actual no es el empleo de la evidencia, sino las obsesiones con los datos numéricos, la tecnología superflua y los limitados objetivos de evaluaciones en lugar de y por encima de cualquier otra cosa, lo cual resulta disfuncional.

Como expresan estos autores, la calidad educativa invita a reflexionar desde diferentes lugares, momentos y perspectivas. Si seguimos poniendo en el centro de la reflexión en otros aspectos (currículos, pruebas, mediciones de aprendizajes, entre otras cosas), no nos permitimos lo esencial y, por tanto, nos desgastamos en discusiones y soluciones que no siempre terminan construyendo respuestas ajustadas a las necesidades.

\section{A modo de cierre}

Los conceptos aquí expresados tienen como propósito de fondo abogar por el bien común. Nos referimos a los valores de la economía humana como sustento fundamental de la educación de niñas y niños. Creemos en la necesidad de trabajar en pro de una educación más equitativa, inclusiva, justa y que desarrolle las potencialidades de todos, pensando en el bien común y teniendo como base que la educación es un derecho.

Como educadores debemos garantizar que las niñas y los niños tengan acceso a una educación de calidad que les posibilite ser actores plenos en la sociedad en que les toque vivir, para lograr un desarrollo integral como personas y convertirse en actores creativos de una sociedad democrática más justa, más humana, conscientes de que forman parte de una comunidad planetaria.

Como plantea Morin: 
[...] habitamos un planeta en el cual las sociedades se han vuelto interdependientes, la toma de conciencia de la comunidad del destino terrestre debe ser el acontecimiento clave del fin de este milenio. Somos solidarios en y con este planeta. Es nuestra tierra-patria. (1993)

\section{Bibliografía}

Anijovich, R., Cappelletti G., Mora S. y Sabelli M. (2008). Transitar la formación pedagógica: Dispositivos y estrategias. Buenos Aires: Paidós.

Buckley, H. E. (2013). El niño pequeño. Recuperado de https://montessoriparatodos.es/blog/un-nino-por-helen-buckley/.

Domenech Francesch, J. (2019). Elogio de la educación lenta. Buenos Aires: Graó.

Educar (2019). En Diccionario etimológico español en línea. Recuperado de http://etimologias.dechile.net/?educar.

Gore, E. y Dunlap, D. (2006). Aprendizaje y organización: Una lectura educativa de teorías de la organización. Buenos Aires: Granica.

Hargreaves, A. y Fullan, M. (2014). Capital profesional: Transformar la enseñanza en cada escuela. Madrid: Morata.

López Boo, F., Araujo, M. C y Tomé, R. (2016). ¿Cómo se mide la calidad de los servicios de cuidado infantil? Washington, D.C.: BID.

Meirieu, P. (2001). La opción de educar. Barcelona: Octaedro.

Morin, E. (2001). Los siete saberes necesarios para la educación del futuro. Buenos Aires: Nueva Visión.

Morin, E., y Pakman, M. (1994). Introducción al pensamiento complejo. Barcelona: Gedisa.

Morin, E. (1993). Terre-Patrie. París: Du Seuil.

Rinaldi, C. (2001). Los pensamientos que apoyan la acción educativa: Una pedagogía que da forma a las cosas y no inhibe la forma de las cosas. En Escuelas infantiles de Reggio Emilia: Historia, filosofía y un proyecto de trabajo (pp. 6-22). Buenos Aires: Novedades Educativas. (0 a 5 la educación en los primeros años, 33).

Uruguay Crece Contigo y Consejo Coordinador de la Educación para la Primera Infancia. (2014). Marco curricular para la atención y educación de niños y niñas uruguayos desde el nacimiento a los seis años. Montevideo: MEC. 